\title{
Doping Knowledge and Attitudes of Turkish Athletes: A Cross-Sectional Study
}

\author{
Omer Ozkan', Serife Seyma Torgutalp', Omer Serkan Kara', Gurhan Donmez', Haydar \\ Demirel $^{1,2}$, Yigitcan Karanfil ${ }^{3}$, Melda Pelin Yargic ${ }^{4}$, Feza Korkusuz ${ }^{1}$ \\ Affiliations: ${ }^{1}$ Hacettepe University, Faculty of Medicine, Department of Sports Medicine, Ankara, Turkey, ${ }^{2}$ Hacettepe \\ University, Faculty of Sport Science, Ankara, Turkey, ${ }^{3}$ Mersin State Hospital, Mersin, Turkey, ${ }^{4}$ Necmettin Erbakan \\ University, Faculty of Medicine, Department of Sports Medicine, Konya, Turkey
}

\begin{abstract}
Correspondence: O. Ozkan, Hacettepe University, Faculty of Medicine, Department of Sports Medicine, 06100, Ankara, Turkey. E-mail: dr.omerozkan@hotmail.com

ABSTRACT The use of prohibited substances in the world of sport, in and out of competition, is a major global problem. A number of similar studies have been conducted in other parts of the world that investigate the knowledge, attitudes, and practices of athletes about doping. The results of those studies cannot entirely be extrapolated to elite Turkish athletes. Therefore, this study aimed to investigate elite athletes' current knowledge of appropriate drug use, doping and use of supplements, and to explore the need for further education on these topics. A total of 202 Turkish athletes participated in this descriptive cross-sectional study. The data were collected through a questionnaire. A five-point Likert scale was used for questions. The most commonly used over-the-counter medications by athletes were painkillers (78.2\%). A remarkable proportion of athletes considered painkillers $(41.1 \%)$, protein powder $(43.1 \%)$, and caffeine $(41.1 \%)$ to be prohibited drugs. According to the athletes, physicians $(84.6 \%)$ and coaches $(78.6 \%)$ were the two most frequently used sources of information, and $87.6 \%$ of the athletes found the physician to be the most reliable source of information. Elite athletes have poor knowledge about doping in Turkey. There is an urgent need for educational anti-doping programmes to address the knowledge gaps observed amongst athletes in this study.
\end{abstract}

KEY WORDS Turkish athletes, doping in sports, surveys and questionnaires

$@ M J S S M o n t e n e g r o$

DOPING KNOWLEDGE AND ATTITUDES OF TURKISH ATHLETES

http://mjssm.me/?sekcija=article\&artid=192

\section{Introduction}

Doping is defined as the use of drugs or other substances to enhance performance, and it has become an important issue in recent years (Bloodworth \& McNamee, 2010). Drug abuse in athletes may involve gaining an advantage in competition, coping with several stressors such as performance anxiety, physical pain, and mental illnesses (Reardon \& Creado, 2014). The use of prohibited substances in athletes in- and out-of-competition is a global problem, causing not only gaining an illicitly competitive advantage in sports, but also severe and harmful health threats, including a wide variety of cardiovascular, psychiatric, metabolic, endocrine, neurologic, infectious, hepatic, renal, and musculoskeletal disorders, and an increased risk of death (Pope et al., 2014).

Since 2004, the World Anti-Doping Agency (WADA) has annually published its "List of Prohibited Substances and Methods", which defines the substances and methods that are prohibited both in- and out-of-competition, and in particular sports ("The Prohibited List | World Anti-Doping Agency," n.d.). Under WADA's Anti-Doping Code, athletes are ultimately responsible for any substance found in their body, regardless of how it got there. The presence of a prohibited substance may result in an anti-doping rule violation, whether its use was intentional or unintentional.

In a review, in which Morente-Sánchez et al. aimed to gather and critically analyse the most recent publications describing elite athletes' attitudes, beliefs, and knowledge of doping in sport, it was found that the athletes mostly receive information about prohibited substances from their coaches, and physicians do not play an essential informative role in this regard (Morente-Sánchez \& Zabala, 2013). According to this study, athletes thought that doping was unethical, harmful and risky for health; however, it would bring them success (Morente-Sán-

Received: August 262019 | Accepted after revision: October 152019 | First published online: March 012020

(C) 2020 by the author(s). License MSA, Podgorica, Montenegro. This article is an open access article distributed under the terms and conditions of the Creative Commons Attribution (CC BY).

Conflict of interest: None declared. 
chez \& Zabala, 2013). Although there are studies about the knowledge and attitudes of athletes in the world, to our knowledge, there is only one study from Turkey. Ozdemir et al. determined the rate of doping and performance-enhancing drug use in 883 subjects and analysed the main reasons for it (Ozdemir et al., 2005). They reported that doping and performance-enhancing drug use was $8 \%$, it was significantly higher (14.5\%) in the athletes, and $52.4 \%$ of doping and performance-enhancing drug users accepted that they were unaware of the drugs full and/or potential side effects (Ozdemir et al., 2005).

There is limited data in the literature on how elite Turkish athletes perceive doping and performance-enhancing drugs. The issue of doping is complex and is presumably predicted by a variety of situational and personal factors, and the results from other countries' studies cannot entirely be extrapolated to elite Turkish athletes. Therefore, this study aimed to evaluate the doping knowledge, attitudes, and behaviour of elite Turkish athletes.

\section{Methods}

\section{Questionnaire}

To investigate the doping knowledge, attitudes and behaviour, data were collected via questionnaire adopted from the study of Malek et al. (2014). The questionnaire was also reviewed and approved by the authors, who are also members of the Turkish Anti-Doping Commission (TADC). The final version of the questionnaire has a total of 10 items and was written in Turkish. A five-point Likert scale was used for questions, in which participants were instructed to respond if they strongly agreed, agreed, disagreed, strongly disagreed or had neutral feelings to the question. Participants were asked questions about which substances they used, whether these substances were banned, their attitudes and awareness about the prohibited substance, whether and from whom they received information about doping and their confidence in these sources of information. The questionnaire was administered from 1 September 2017 to 1 September 2018. The questionnaire was validated using face and content validity methods. The reliability of the questionnaire was calculated using Cronbach's alpha coefficient $(\alpha=0.88)$.

\section{Participants}

A total of 202 elite Turkish athletes, over 18 years of age, from 11 sports including ice hockey, soccer, swimming, diving, basketball, Muay Thai, weightlifting, volleyball, cycling, track and field, and taekwondo enrolled for this study. Participants who had retired from a sport or those who had not participated in a competitive game or competition in the past year were excluded. Verbal information about the aims and objectives of the study was given to athletes before their participation. After this information, written and oral consents were received from all athletes who agreed to participate in this study. The questionnaires were anonymous, and the data were kept confidential to protect the privacy of the participants. This study was approved by the local ethics committee of the Hacettepe University Human Ethics Committee (Decision number: GO 17/680-17).

\section{Statistics}

Statistical analyses were performed using the SPSS software version 21 (SPSS, Chicago, IL, United States). All data were expressed as mean and standard deviation or frequencies and percentages, depending on the characteristics of the variables.

\section{Results}

\section{Demographic Characteristics}

The mean age of the athletes was $20.8 \pm 3.61$ years, and the majority of the interviewed athletes were male $(\mathrm{n}=139,68.8 \%)$. The distribution of athletes by type of sports was; 39 in ice hockey $(19.3 \%), 33$ in soccer

\begin{tabular}{lccc}
\multicolumn{1}{l}{ TABLE 1. Distribution of the athletes according to sport type and doping training status } \\
& & $\mathbf{n}$ & $\%$ \\
\hline Sports type & Ice hockey & 39 & 19.3 \\
$(\mathrm{~N}=202)$ & Soccer & 33 & 16.3 \\
& Swimming & 29 & 14.4 \\
& Diving & 25 & 12.4 \\
& Basketball & 21 & 10.4 \\
& Muay Thai & 17 & 8.4 \\
& Weightlifting & 16 & 7.9 \\
& Volleyball & 13 & 6.4 \\
& Cycling & 6 & 3.0 \\
& Track and field & 2 & 1.0 \\
Taekwondo & 1 & 0.5 \\
\hline Education (N=202) & Yes & & \\
& No & 43 & 21.3 \\
& Have you ever had education about doping? & 159 & 78.7 \\
\hline
\end{tabular}


(16.3\%), 29 in swimming (14.4\%), 25 in diving (12.4\%), 21 in basketball (10.4\%), 17 in Muay Thai (8,4\%), 16 in weightlifting (7,9\%), 13 in volleyball (6.4\%), 6 in cycling (3.0\%), 2 in track and field (1.0\%) and 1 in taekwondo (0,5\%) (Table 1$)$.

TABLE 2. Medications or supplements used by the athletes in the previous 12 months

\begin{tabular}{lcccccc} 
Drugs & \multicolumn{2}{c}{ I used last year } & \multicolumn{2}{c}{ I did not use last year } & \multicolumn{3}{c}{ I don' t remember } \\
\cline { 2 - 6 } $\mathbf{N = 2 0 2}$ & $\mathbf{n}$ & \% & $\mathbf{n}$ & \% & $\mathbf{n}$ & \% \\
\hline Pain killers & 158 & 78.2 & 35 & 17.3 & 9 & 4.5 \\
Cough and cold medications & 131 & 64.9 & 58 & 28.7 & 13 & 6.4 \\
Antibiotics & 112 & 55.4 & 72 & 35.6 & 18 & 8.9 \\
Multivitamin & 104 & 51.5 & 84 & 41.6 & 14 & 6.9 \\
Caffeine & 78 & 38.6 & 103 & 51.0 & 21 & 10.4 \\
Protein powder & 62 & 30.7 & 126 & 62.4 & 14 & 6.9 \\
Creatinine & 38 & 18.8 & 122 & 60.4 & 42 & 20.8 \\
Allergy medications & 36 & 17.8 & 145 & 71.8 & 21 & 10.4 \\
L-carnitine & 30 & 14.9 & 130 & 64.4 & 42 & 20.8 \\
Diuretics & 8 & 4.0 & 167 & 82.7 & 27 & 13.4 \\
Asthmatic medications & 5 & 2.5 & 177 & 87.6 & 20 & 9.9 \\
Insulin & 5 & 2.5 & 172 & 85.1 & 25 & 12.4 \\
Antidepressants & 4 & 2.0 & 171 & 84.7 & 27 & 13.4 \\
Contraceptive pills & 3 & 1.5 & 178 & 88.1 & 21 & 10.4 \\
Thyroid medications & 1 & 0.5 & 169 & 83.7 & 32 & 15.8 \\
\hline
\end{tabular}

\section{Medication Usage}

Participants were asked to choose which medications or supplements (from a provided list) they had used in the previous 12 months (Table 2). The most commonly used over-the-counter medications were for pain (78.2\%), cough and cold (64.9\%), while the percentage of antibiotic usage was $55.4 \%$.

\section{Medication Awareness for Doping Violation}

Three-quarters of respondents (159, 78.7\%) declared that they did not obtain any education regarding doping (Table 1). Participants were asked whether these medications or supplements were prohibited by WADA for causing a doping violation (Table 3). The most common substance considered to be prohibited was protein-powders $(43.1 \%)$, followed by caffeine $(41.1 \%)$, painkillers $(41.1 \%)$, and antidepressants (39.6\%). Participants mostly had no knowledge about diuretics (51.5\%), thyroid medications (49.0\%), creatinine (48.5\%), L-carnitine (47.5\%) and contraceptive pills (46.5\%).

TABLE 3. Athletes' awareness of medications or supplements prohibited by WADA for causing a doping violation

\begin{tabular}{|c|c|c|c|c|c|c|}
\hline \multirow{2}{*}{$\mathrm{N}=\mathbf{2 0 2}$} & \multicolumn{2}{|c|}{ Includes doping } & \multicolumn{2}{|c|}{ Not include doping } & \multicolumn{2}{|c|}{ I don't know } \\
\hline & $\mathbf{n}$ & $\%$ & $\mathbf{n}$ & $\%$ & $\mathbf{n}$ & $\%$ \\
\hline Protein-powders & 87 & 43.1 & 70 & 34.7 & 45 & 22.3 \\
\hline Caffeine & 83 & 41.1 & 60 & 29.7 & 59 & 29.2 \\
\hline Pain killers & 83 & 41.1 & 69 & 34.2 & 50 & 24.8 \\
\hline Antidepressants & 80 & 39.6 & 39 & 19.3 & 83 & 41.1 \\
\hline Antibiotics & 73 & 36.1 & 68 & 33.7 & 61 & 30.2 \\
\hline Cough and cold medications & 67 & 33.2 & 76 & 37.6 & 59 & 29.2 \\
\hline Insulin & 58 & 28.7 & 54 & 26.7 & 90 & 44.6 \\
\hline Thyroid medications & 57 & 28.2 & 46 & 22.8 & 99 & 49.0 \\
\hline Multivitamin & 53 & 26.2 & 96 & 47.5 & 53 & 26.2 \\
\hline Creatinine & 51 & 25.2 & 53 & 26.2 & 98 & 48.5 \\
\hline Diuretics & 51 & 25.2 & 47 & 23.3 & 104 & 51.5 \\
\hline Allergy medications & 51 & 25.2 & 75 & 37.1 & 76 & 37.6 \\
\hline Contraceptive pills & 47 & 23.3 & 61 & 30.2 & 94 & 46.5 \\
\hline Asthmatic medications & 46 & 22.8 & 73 & 36.1 & 83 & 41.1 \\
\hline L-carnitine & 44 & 21.8 & 62 & 30.7 & 96 & 47.5 \\
\hline
\end{tabular}


TABLE 4. Athletes' attitudes and awareness of prohibited substances

\begin{tabular}{|c|c|c|c|c|c|c|c|c|c|c|}
\hline \multirow{2}{*}{$\mathrm{N}=\mathbf{2 0 2}$} & \multicolumn{2}{|c|}{ Strongly agree } & \multicolumn{2}{|c|}{ Agree } & \multicolumn{2}{|c|}{ Disagree } & \multicolumn{2}{|c|}{ Strongly disagree } & \multicolumn{2}{|c|}{ Unsure } \\
\hline & $\mathbf{n}$ & $\%$ & $\mathbf{n}$ & $\%$ & $\mathbf{n}$ & $\%$ & $\mathbf{n}$ & $\%$ & $\mathbf{n}$ & $\%$ \\
\hline Doping is not worth the risk. & 119 & 58.9 & 44 & 21.8 & 5 & 2.5 & 22 & 10.9 & 12 & 5.9 \\
\hline I am aware of the substances I cannot use in competition. & 113 & 55.9 & 66 & 32.7 & 7 & 3.5 & 2 & 1.0 & 14 & 6.9 \\
\hline $\begin{array}{l}\text { When the medication is prescribed by the doctor for } \\
\text { another condition, I declare that I am an athlete. }\end{array}$ & 109 & 54.0 & 65 & 32.2 & 10 & 5.0 & 7 & 3.5 & 11 & 5.4 \\
\hline I am aware of the substances I cannot use out of competition. & 100 & 49.5 & 65 & 32.2 & 7 & 3.5 & 4 & 2.0 & 26 & 12.9 \\
\hline $\begin{array}{l}\text { When getting a prescription medication, I often seek } \\
\text { information from the pharmacist. }\end{array}$ & 83 & 41.1 & 76 & 37.6 & 13 & 6.4 & 9 & 4.5 & 21 & 10.4 \\
\hline $\begin{array}{l}\text { When getting a nonprescription medication or supplement, } \\
\text { I consult a pharmacist each time. }\end{array}$ & 81 & 40.1 & 65 & 32.2 & 18 & 8.9 & 16 & 7.9 & 22 & 10.9 \\
\hline $\begin{array}{l}\text { A physician would be a useful source of information about } \\
\text { banned substances. }\end{array}$ & 80 & 39.6 & 74 & 36.6 & 21 & 10.4 & 13 & 6.4 & 14 & 6.9 \\
\hline $\begin{array}{l}\text { When using a medication or supplement, I am concerned } \\
\text { about the possibility of a doping violation. }\end{array}$ & 63 & 31.3 & 58 & 28.9 & 32 & 15.9 & 19 & 9.5 & 29 & 14.4 \\
\hline Most athletes competing are not using banned substances. & 47 & 23.3 & 55 & 27.2 & 54 & 26.7 & 12 & 5.9 & 34 & 16.8 \\
\hline My performance would be improved by banned substances. & 19 & 9.4 & 31 & 15.3 & 61 & 30.2 & 69 & 34.2 & 22 & 10.9 \\
\hline Doping is necessary to achieve the best results. & 14 & 6.9 & 13 & 6.4 & 45 & 22.3 & 113 & 55.9 & 17 & 8.4 \\
\hline I feel pressure to use banned substances. & 10 & 5.0 & 9 & 4.5 & 58 & 28.7 & 108 & 53.5 & 17 & 8.4 \\
\hline
\end{tabular}

Attitudes and Awareness about Prohibited Substances

Table 4 summarizes the athletes' responses to their attitudes and awareness about prohibited substances. A majority of the athletes thought that they had an awareness of the substances that should not be used during both in $(88.6 \%)$ and out $(81.7 \%)$ of competition. Most of the participants $(67.3 \%)$ don't believe that most of their colleagues and competitors use prohibited substances (except disagree and strongly disagree in Table 4). Participants generally thought that doping is not necessary to achieve the best results ( $86.6 \%)$, and they mostly did not feel pressure to use prohibited substances (90.6\%). A significant number of participants were not certain about what they are or are not allowed to take regarding medication or supplements (39.6\%).

Sources of Doping Information and Reliability of Sources

A list of sources of information was provided to participants for rating the frequency of the source of information (Table 5). The most common source of information about doping was physicians (84.6\%), followed by coaches (78.6\%), pharmacists (70.1\%), and team-mates (67.0\%). In contrast, WADA (57.3\%) and TADC (55.0\%) were some of the least sources used for information. According to the participants, the physician was declared to be the most reliable source of information about prohibited substances and doping (96.5\%, neutral and more) (Table 6). The web pages other than WADA, TADC and sports federations were the least reliable source of information (57.5\%, neutral and more), followed by their teammates ( $71.7 \%$, neutral and more).

\section{Discussion}

Various sports have captured the attention of spectators. With growing interest, the financial value of the global sports market has significantly increased and is estimated to be worth around $\$ 600-700$ billion per year (Au,

\begin{tabular}{lcccccccccc}
\multicolumn{1}{l}{ TABLE 5. Sources of information used by athletes about doping } \\
\cline { 2 - 13 } N=202 & \multicolumn{2}{c}{ Always } & \multicolumn{2}{c}{ Often } & \multicolumn{2}{c}{ Sometimes } & \multicolumn{2}{c}{ Rarely } & \multicolumn{2}{c}{ Never } \\
\cline { 2 - 13 } & $\mathbf{n}$ & $\%$ & $\mathbf{n}$ & $\%$ & $\mathbf{n}$ & $\%$ & $\mathbf{n}$ & $\%$ & $\mathbf{n}$ & $\%$ \\
\hline Physician & 63 & 31.3 & 48 & 23.9 & 45 & 22.4 & 14 & 7.0 & 31 & 15.4 \\
Coach & 49 & 24.4 & 34 & 16.9 & 53 & 26.4 & 22 & 10.9 & 43 & 21.4 \\
WADA & 34 & 17.1 & 25 & 12.6 & 35 & 17.6 & 20 & 10.1 & 85 & 42.7 \\
TADC & 34 & 17.0 & 16 & 8.0 & 39 & 19.5 & 21 & 10.5 & 90 & 45.0 \\
Pharmacist & 28 & 13.9 & 31 & 15.4 & 40 & 19.9 & 42 & 20.9 & 60 & 29.9 \\
Federation & 28 & 13.9 & 23 & 11.4 & 34 & 16.9 & 31 & 15.4 & 85 & 42.3 \\
Physiotherapist & 25 & 12.5 & 27 & 13.5 & 32 & 16.0 & 26 & 13.0 & 90 & 45.0 \\
Other & 19 & 9.5 & 23 & 11.6 & 39 & 19.6 & 43 & 21.6 & 75 & 37.7 \\
Webpages & 16 & 8.0 & 15 & 7.5 & 40 & 20.0 & 25 & 12.5 & 104 & 52.0 \\
Teammate & 15 & 7.5 & 34 & 17.0 & 50 & 25.0 & 35 & 17.5 & 66 & 33.0 \\
\hline
\end{tabular}

Note: WADA=World Anti-Doping Agency, TADC=Turkish Anti-Doping Commission. 
TABLE 6. Reliability of sources used by athletes about doping

\begin{tabular}{lcccccccccc} 
& \multicolumn{2}{c}{ Strongly trustful } & \multicolumn{2}{c}{ Trustful } & \multicolumn{2}{c}{ Neutral } & \multicolumn{2}{c}{ Untrustful } & \multicolumn{2}{c}{ Strongly untrustful } \\
\cline { 2 - 11 } & $\mathbf{n}$ & $\mathbf{\%}$ & $\mathbf{n}$ & $\%$ & $\mathbf{n}$ & $\%$ & $\mathbf{n}$ & $\%$ & $\mathbf{n}$ & $\%$ \\
\hline Physician & 122 & 60.7 & 54 & 26.9 & 18 & 9.0 & 4 & 2.0 & 3 & 1.5 \\
WADA & 101 & 50.5 & 39 & 19.5 & 37 & 18.5 & 10 & 5.0 & 13 & 6.5 \\
TADC & 98 & 49.0 & 55 & 27.5 & 30 & 15.0 & 4 & 2.0 & 13 & 6.5 \\
Coach & 87 & 43.7 & 54 & 27.1 & 42 & 21.1 & 4 & 2.0 & 12 & 6.0 \\
Federation & 63 & 31.7 & 50 & 25.1 & 50 & 25.1 & 17 & 8.5 & 19 & 9.5 \\
Pharmacist & 62 & 30.8 & 66 & 32.8 & 47 & 23.4 & 13 & 6.5 & 13 & 6.5 \\
Physiotherapist & 61 & 30.5 & 64 & 32.0 & 32 & 16.0 & 22 & 11.0 & 21 & 10.5 \\
Teammate & 35 & 17.7 & 25 & 12.6 & 82 & 41.4 & 21 & 10.6 & 35 & 17.7 \\
Other & 32 & 16.1 & 55 & 27.6 & 66 & 33.2 & 22 & 11.1 & 24 & 12.1 \\
Web pages & 23 & 11.5 & 39 & 19.5 & 53 & 26.5 & 29 & 14.5 & 56 & 28.0 \\
\hline
\end{tabular}

Note: WADA=World Anti-Doping Agency, TADC=Turkish Anti-Doping Commission.

2017). Therefore, athletes face the thorny situation in which it is desired that they be "better, stronger, and faster". However, in the interest of the athletes' health, it is obligatory to control and limit medication or supplements by which sports performance can be improved and which are prohibited by WADA (Petróczi \& Strauss, 2015). Therefore, because prohibited substances are entered onto the existing list annually, it is necessary to determine whether athletes are aware of doping and their perception regarding it. With that in mind, this study was aimed to investigate the perceptions and awareness of athletes on the use of prohibited substances, whether they received any information about doping, from which source they received the information and the reliability of these sources.

The most striking result to emerge from our study's data was that $78.7 \%$ of the athletes did not obtain any education regarding doping. Although our results differed considerably from those of Moran et al. (2008), in which athletes from 16 different countries stated that $62.6 \%$ of them received information regarding prohibited substances in their sports, these values correlate favourably with the study of Muwonge et al. (2015), who found that $60 \%$ of Ugandan professional athletes participating in different types of sports were familiar with information on doping, but $80 \%$ of them could not give a definition of doping. In a more recent study by Murofushi et al. (2018), results showed that $30.1 \%$ of Japanese university athletes had received an anti-doping education at least once, and $20.8 \%$ more than once. Perhaps the results of the present paper differ from the results of previous studies because WADA accredited the laboratory in our country later in comparison with the other countries. Therefore, doping education among the athletes started later on. In 2018, to promote education about Health and Anti-Doping among athletes, coaches, and others, WADA launched a new learning platform the Anti-Doping e-Learning platform (ADeL) ("WADA launches new anti-doping eLearning platform (ADeL) | World Anti-Doping Agency," 2018). This anti-doping programme may increase the awareness of athletes about banned substances in the long term.

Most elite athletes, especially during competitions, use some medications and supplements to improve their performance (Burke, 2017) or to influence musculotendinous healing during recovery (Tack, Shorthouse, \& Kass, 2018). During the 2016 Rio Olympic Games, Soligard et al. recorded the injury and illness rate of athletes and found 9.8 injuries and 5.4 illnesses per 100 athletes over the 17-day period [16]. In our study, when athletes were asked about which medication they use, $78.2 \%$ reported that they used over-the-counter painkillers, followed by a cough and cold drugs (64.9\%) and antibiotics (55.4\%).

The results of the present paper are similar to those of Tscholl et al., (2010) who reported that NSAIDs, respiratory drugs, and analgesics were more frequently used. A further epidemiology study carried out by Tscholl et al. (2015) concurred with the findings of the present paper, reporting that the mean medication intake of male football players was 0.77 substances per player and per match.

Regarding the supplements used by athletes, in the present study, $30.7 \%$ of the participants reported consuming protein-powder, while more than half of the participants (51.5\%) reported using multivitamins. In 2000, during the doping control at the Sydney Olympics, athletes stated the use of 26 separate supplements in a single day (Corrigan \& Kazlauskas, 2003). The athletes thought that they were aware of substances that were allowed to be used within and outside the competition, despite their high drug use. ( $88.6 \%$ and $81.7 \%$, respectively) (Corrigan \& Kazlauskas, 2003). In the present study, almost half (43.1\%) of the participants considered protein powder and $41.1 \%$ caffeine to be prohibited substances by WADA for causing a doping violation. The same lack of awareness regarding doping among high-level football players has also been supported by Ama et al. (2003).

Since the 1990s, creatinine has become one of the most popular supplement to improve athletic performance (Hall \& Trojian, 2013). However, in our study, only $26.2 \%$ of the athletes did not consider creatinine to be a prohibited substance, while $48.5 \%$ of the athletes did not know about this. Taking into consideration the abovementioned, education or obtaining information from reliable sources are very important for the athlete's 
career. The results of our study show that the physician was seen as the most frequently consulted (\%84.6) and reliable (96.5\%, neutral and more) source of doping knowledge by the athletes. Our findings are in contradiction with previous studies on French high school athletes and Iranian athletes, who declared their peers and coaches to be the primary sources about doping (Seif Barghi, Halabchi, Dvorak, \& Hosseinnejad, 2015; Backhouse, Kenna, Robinson, \& Atkin, 2007). It is important to note that physicians have the potential to influence athletes with regards to doping information. Thus, to ensure that athletes receive accurate information about doping, they must update their knowledge of prohibited substances and develop trustworthy relationships with the athletes.

Another reassuring finding of our study was that athletes have negative perceptions toward using prohibited substances to achieve better results and that $82.2 \%$ of them feel no pressure to use any doping substance. Furthermore, $80.7 \%$ of the participants stated that doping was not worth the risk. This confirms the previous finding in the literature (Malek et al., 2014).

In conclusion, the present study provides information about the doping knowledge and attitudes of Turkish athletes. According to the results, more than two thirds of these athletes did not receive doping training during their career. There is an urgent need to increase the awareness and the knowledge of athletes in the prevention of the usage of prohibited substances. Furthermore, it is necessary to provide educational programmes not only for the athletes but also to the physicians, coaches and other personnel in the athlete's team, and a professional development plan should be implemented to ensure that the information remains accurate and up-to-date.

\section{References}

Ama, P. F. M., Betnga, B., Ama Moor, V. J., \& Kamga, J. P. (2003). Football and doping: study of African amateur footballers. British Journal of Sports Medicine, 37(4), 307-310. doi: 10.1136/BJSM.37.4.307

Backhouse, D. S., Kenna, P. J., Robinson, P. S., \& Atkin, M. A. (2007). Attitudes, Behaviours, Knowledge and Education - Drugs in Sport: Past, Present and Future. Carnegie Research Institute Leeds Metropolitan - World Anti-Doping Agency, 1-199. Retrieved from http://www.wada-ama.org/rtecontent/document/ backhouse_et_al_full_report.pdf

Bloodworth, A., \& McNamee, M. (2010). Clean Olympians? Doping and anti-doping: The views of talented young British athletes. International Journal of Drug Policy, 21(4), 276-282. doi: 10.1016/j.drugpo.2009.11.009

Burke, L. M. (2017). Practical Issues in Evidence-Based Use of Performance Supplements: Supplement Interactions, Repeated Use and Individual Responses. Sports Medicine, 47(S1), 79-100. doi: 10.1007/s40279017-0687-1

Corrigan, B., \& Kazlauskas, R. (2003). Medication use in athletes selected for doping control at the Sydney Olympics (2000). Clinical Journal of Sport Medicine: Official Journal of the Canadian Academy of Sport Medicine, 13(1), 33-40.

Hall, M., \& Trojian, T. H. (2013). Creatine Supplementation. Current Sports Medicine Reports, 12(4), 240-244. doi: 10.1249/JSR.0b013e31829cdff2

Malek, S., Taylor, J., \& Mansell, K. (2014). A questionnaire examining attitudes of collegiate athletes toward doping and pharmacists as information providers. Canadian Pharmacists Journal / Revue Des Pharmaciens Du Canada, 147(6), 352-358. doi: 10.1177/1715163514552559

Moran, A., Guerin, S., Kirby, K., \& MacIntyre, T. (2008). The development and validation of a doping attitudes and behaviour scale. Newtownabbey: School of Sports Studies, University of Ulster.

Morente-Sánchez, J., \& Zabala, M. (2013). Doping in Sport: A Review of Elite Athletes' Attitudes, Beliefs, and Knowledge. Sports Medicine, 43(6), 395-411. doi: 10.1007/s40279-013-0037-x

Murofushi, Y., Kawata, Y., Kamimura, A., Hirosawa, M., \& Shibata, N. (2018). Impact of anti-doping education and doping control experience on anti-doping knowledge in Japanese university athletes: a crosssectional study. Substance Abuse Treatment, Prevention, and Policy, 13(1), 44. doi: 10.1186/s13011-0180178-x

Muwonge, H., Zavuga, R., \& Kabenge, P. A. (2015). Doping knowledge, attitudes, and practices of Ugandan athletes': a cross-sectional study. Substance Abuse Treatment, Prevention, and Policy, 10(1), 37. doi: 10.1186/s13011-015-0033-2

Ozdemir, L., Nur, N., Bagcivan, I., Bulut, O., Sümer, H., \& Tezeren, G. (2005). Doping and performance enhancing drug use in athletes living in sivas, mid-anatolia: a brief report. Journal of Sports Science \& Medicine, 4(3), 248-252.

Petróczi, A., \& Strauss, B. (2015). Understanding the psychology behind performance-enhancement by doping. Psychology of Sport and Exercise, 16, 137-139. doi: 10.1016/j.psychsport.2014.09.002

Pope, H. G., Wood, R. I., Rogol, A., Nyberg, F., Bowers, L., Bhasin, S., \& Bhasin, S. (2014). Adverse health consequences of performance-enhancing drugs: an Endocrine Society scientific statement. Endocrine Reviews, 35(3), 341-375. doi: 10.1210/er.2013-1058

Reardon, C. L., \& Creado, S. (2014). Drug abuse in athletes. Substance Abuse and Rehabilitation, 5, 95-105. doi: 10.2147/SAR.S53784

Seif Barghi, T., Halabchi, F., Dvorak, J., \& Hosseinnejad, H. (2015). How the Iranian Football Coaches and Players Know About Doping? Asian Journal of Sports Medicine, 6(2), e24392. doi: 10.5812/asjsm.6(2)2015.24392 
Tack, C., Shorthouse, F., \& Kass, L. (2018). The Physiological Mechanisms of Effect of Vitamins and Amino Acids on Tendon and Muscle Healing: A Systematic Review. International Journal of Sport Nutrition and Exercise Metabolism, 28(3), 294-311. doi: 10.1123/ijsnem.2017-0267

The Prohibited List | World Anti-Doping Agency. (n.d.).

Timothy Au. (2017). As remarkable growth of sports industry continues, exclusive data analysis reveals the key trademark trends. Available at: https://www.worldtrademarkreview.com/brand-management/remarkable-growth-sports-industry-continues-exclusive-data-analysis-reveals

Tscholl, P., Alonso, J. M., Dollé, G., Junge, A., \& Dvorak, J. (2010). The Use of Drugs and Nutritional Supplements in Top-Level Track and Field Athletes. The American Journal of Sports Medicine, 38(1), 133-140. doi: $10.1177 / 0363546509344071$

Tscholl, P. M., Vaso, M., Weber, A., \& Dvorak, J. (2015). High prevalence of medication use in professional football tournaments including the World Cups between 2002 and 2014: a narrative review with a focus on NSAIDs. British Journal of Sports Medicine, 49(9), 580-582. doi: 10.1136/bjsports-2015-094784

WADA launches new anti-doping eLearning platform (ADeL) | World Anti-Doping Agency. (2018). Available at: https://www.wada-ama.org/en/media/news/2018-01/wada-launches-new-anti-doping-elearning-platform-adel 